\title{
Technical and Social Evaluation of Arsenic Mitigation in Rural Bangladesh
}

\author{
Md. Shafiquzzaman', Md. Shafiul Azam', lori Mishima², and Jun Nakajima' \\ 'Department of Environmental Systems Engineering, Ritsumeikan University, I I - I Nojihigashi, Kusatsu, \\ Shiga 525-8577, Japan and ${ }^{2}$ Center for Environmental Science in Saitama, 914 Kamitanadare, \\ Kisai-machi, Kita-Saitama-gun, Saitama 347-0 I I5, Japan
}

\begin{abstract}
Technical and social performances of an arsenic-removal technology-the sono arsenic filter-in rural areas of Bangladesh were investigated. Results of arsenic field-test showed that filtered water met the Bangladesh standard $(<50 \mu \mathrm{g} / \mathrm{L})$ after two years of continuous use. A questionnaire was administrated among 198 sono arsenic filter-user and 230 non-user families. Seventy-two percent of filters ( $\mathrm{n}=198)$ were working at the time of the survey. Another $28 \%$ of the filters were abandoned due to breakage. The abandonment percentage (28\%) was lower than other mitigation options currently implemented in Bangladesh. Households were reluctant to repair the broken filters on their own. High cost, problems with maintenance of filters, weak sludge-disposal guidance, and slow flow rate were the other demerits of the filter. These results indicate that the implementation approaches of the sono arsenic filter suffered from lack of ownership and long-term sustainability. Continuous use of arsenic-contaminated tubewells by the non-user households demonstrated the lack of alternative water supply in the survey area. Willingness of households to pay (about 30\%) and preference of household filter (50\%) suggest the need to develop a low-cost household arsenic filter. Development of community-based organization would be also necessary to implement a long-term, sustainable plan for household-based technology.
\end{abstract}

Key words: Arsenic; Arsenic contamination; Drinking-water; Evaluation studies; Social development; Sono arsenic filter; Sustainability; Water pollution; Bangladesh

\section{INTRODUCTION}

In the last two decades, introduction of shallow tubewells has given over access to clean and hygienic drinking-water to $95 \%$ of the rural households of Bangladesh. However, the contamination of shallow aquifers with arsenic is a serious threat to public health in Bangladesh. A national survey in 1998 and 1999 estimated that the water in about $27 \%$ of all tubewells $(n=3,534)$ exceeded the arsenic limit of $50 \mu \mathrm{g} / \mathrm{L}$ set by the Government of Bangladesh, and this figure rises to $46 \%$ if the World Health Organization (WHO) guideline of

Correspondence and reprint requests should be addressed to:

Md. Shafiquzzaman

Department of Environmental Systems Engineering

Ritsumeikan University

1-1-1 Nojihigashi, Kusatsu

Shiga 525-8577

Japan

Email: shafiq@se.ritsumei.ac.jp OR

khokon_k@yahoo.com

Fax: +81-77-561-3983 maximum permissible level of arsenic in drinkingwater $(10 \mu \mathrm{g} / \mathrm{L})$ was used (1). Results of a blanketscreening programme in 270 most affected subdistricts (upazilas), in which 4.73 million tubewells in 54,041 villages were tested for arsenic, showed that $29.1 \%$ of the tubewells had arsenic in excess of the Bangladesh standard (2). The detailed map and upazila-wise summary of the screening results could be found in the website of the Bangladesh Arsenic Mitigation Water Supply Projects (BAMWSP) (2). While the figures are unconfirmed, an estimated 35-40 million of 130 million people are potentially at risk of arsenic poisoning from drinkingwater source in Bangladesh (3-4).

A large number of people affected with arsenicrelated diseases, ranging from melanosis to skin cancer and gangrene, have been identified in rural Bangladesh. A recent report mentioned that longterm exposure to present arsenic concentrations will result in nearly 125,000 cases of skin cancer and about 3,000 fatalities each year (5). The lifetime excess risk (per 100,000 people) of mortality from 
liver, bladder and lung cancers attributed to arsenic in drinking-water were 198.3 for males and 53.8 for females, with an average across-gender lifetime risk of 126.1 (6). It is, thus, urgently needed to find the effective, acceptable and sustainable solutions to address the problem of arsenic contamination.

Arsenic-mitigation efforts have so far been concentrated on identification of contaminated and safe tubewells, creation of public awareness, and identification of cases of arsenic-related health problem. The Government of Bangladesh is currently promoting alternative water options. The National Policy for Arsenic Mitigation and Implementation Plan for Arsenic Mitigation in Bangladesh have promoted the use of dugwells, pond-sand filters, rainwater harvesting, and deep tubewells as alternative arsenic-free water-supply options (7). Piped water schemes, using either groundwater or surface water, have also been promoted.

In addition, many aid organizations have implemented household-based arsenic-removal filters. Several household arsenic-removal technologies have been tried out in rural Bangladesh. Among them, many household technologies have some serious drawbacks, including troublesome maintenance, high costs, and insufficient treatment rate. Sono arsenic filter (SAF) is one of the promising technologies in Bangladesh, which has received a lot of attention by users, scientists, and researchers (8). Recently, the SAF received the highest award from the National Academy of Engineering-Grainger challenge prize for sustainability (9). The SAF is a modified form of the popular 3-kolshi/pithcer arsenic filter. The filter consists of two buckets. A 4-5-cm thick layer of composite iron (mixture of metal iron and iron hydroxides) covered by sand-layers is set at the middle of the upper bucket, where arsenic is adsorbed and co-precipitated. The lower bucket contains sand and a charcoal-layer to remove the iron hydroxides, and organic matter is released form the upper bucket. The final filtered water is collected at the bottom of the lower bucket. The details of the chemistry and arsenic-removal mechanism of the SAF have been reported elsewhere (8). Cost of the actual filter was around US\$ 45-50 (US\$ 1 is about Tk 70) (8). A local non-governmental organization (NGO)ADAMS - in Khulna, Bangladesh, installed over 1,000 SAFs in Mollahat subdistrict of Bagerhat district of Bangladesh in 2004 with external aid. Beneficiaries paid Tk 150 each for the filter. After installation, little attention was paid to the monitoring of quality of water, arsenic-removal performance, and social acceptance of the SAF. Therefore, installation approaches of SAF were not evaluated for long-term sustainability.

This research was aimed at evaluating the arsenicremoval performance of SAF and its social acceptance in rural Bangladesh. Arsenic was measured on-site by arsenic test-kits. Four hundred and twenty-eight households were selected, and a questionnaire survey was carried out in six villages in Mollahat subdistrict of Bagerhat district, southern district in Bangladesh. The overall results obtained from this research could facilitate the development of the new cost-effective and sustainable arsenic-removal technologies.

\section{MATERIALS AND METHODS}

\section{Survey method}

A questionnaire survey was designed to gather detailed information on the performance and acceptance of SAF and other alternative water sources. The interest of the study was not only evaluation of SAF but also investigation of other technologies, such as deep tubewells. Household's preference of technologies and willingness to pay, together with past and present situation of water-usage, were also investigated. Other aspects on which data were collected included source of water, demand of daily water, occupation, monthly income, and education.

During 31 August-6 September 2006, a combined team of Ritsumeikan University, Japan, Khulna University of Engineering and Technology (KUET), Bangladesh, and ADAMS, a local NGO in Khulna conducted the survey. In total, 428 households from six unions/villages-Atjuri, Chunkhola, Gangni, Gawola, Kulia, and Udaypur-in Mollahat subdistrict of Bagerhat, were chosen for the survey. This area is one of the highly arsenic-contaminated regions in Bangladesh (2). BAMWSP field-kit testing has shown that $79 \%$ of 6,762 tubewells contained $50 \mu \mathrm{g} / \mathrm{L}$ of arsenic in this area (2). In total, 103 arsenic patients were identified from 146,810 people in this area (2).

Selection of households was based on the SAF distribution list. Initially, households were divided into SAF-user and non-user families. One hundred and ninety-eight SAF users were randomly listed from the 1,000 SAF distribution list using the Microsoft Excel data analysis program (Random Number Generation Tools). Two hundred and thirty nonuser households were selected based on the ran- 
domized list of SAF-users at the ratio nearly about $1: 1$, i.e. at least one, sometimes two, households was/were selected near each SAF-user household. After interviews, households were finally divided into 142 sono filter-users (SFUs) who were currently using SAF, 81 deep tubewell-users (DTUs) who were using DTWs, including abandoned SAF-users, and 205 non-users (NUs) who were using none of the technologies, including abandoned SAF-users. In total, 54 questions were designed in six questionnaire sections. Three separate questionnaire sections were designed for SFUs, NUs, and DTUs with three common questionnaire sections for all the groups. From each selected household, one individual was interviewed. In 99\% of cases $(n=428)$, the respondents were housewives because, in families, women are familiar with the current arsenic technologies. The housewives handle arsenic filters, and they also have to collect water from the sources.

Six groups conducted the interview. Each group consisted of at least one representative from Ritsumeikan University, KUET, and ADAMS each. A face-toface interview was conducted with the respondents, and it took about half an hour to complete each interview. The Microsoft Excel program was used for entry and analysis of all preliminary data.

\section{Field measurement of arsenic}

Earlier, BAMWSP field-kit arsenic-testing was conducted in this area (2). After testing, the tubewells were painted red for arsenic-risk and green for arsenic-safe tubewell. However, the paint marks disappeared, and the households did not remember the safe and contaminated tubewells during our investigation. In total, 95 tubwell, $41 \mathrm{SAF}$ and 20 DTW water samples were tested in this survey. Forty-one SAFs were randomly selected based on the selected list of 198 SFUs. Water samples were collected from 95 tubewells-41 from SFUs and 54 from NUs, during the interview. Twenty water samples from DTWs were also tested to see whether they were contaminated or safe. Tubewell water was collected in sampling-pots after pumping the water for about 3 or 4 minutes to avoid the oxidation or sedimentation of arsenic. Filtered water was collected in sampling-pots from the effluent tap of SAF. Arsenic in tubewells water and filtered water was measured on-site using commercial arsenic field test-kits (Gastec). Concentration of arsenic was determined from the calibration table according to the rate of change of colour with time due to arsine gas production from contaminated water. Arsine gas was produced immediately after adding acid, $\mathrm{SnCl}_{2}$, and zinc coarse powder into the sample water. Some water samples were carried to the laboratory and analyzed for arsenic with atomic adsorption spectrophotometer (AAS). Figure 1 shows the results of the test-kits and AAS. A good correlation between test-kits and AAS arsenic measurement was obtained with $\mathrm{R}^{2}$ value of 0.8929 .

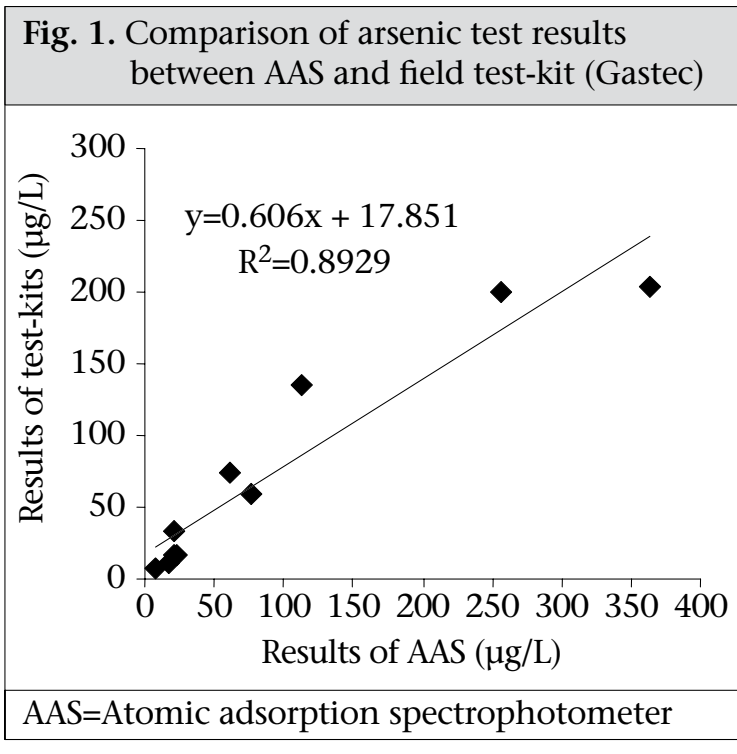

RESULTS

Socioeconomic profile of the survey area

To understand the reasons for rejection of technology, preferred technology of household, and willingness to pay for safe water, it is important to gather information on the socioeconomic characteristics of the population covered in the survey. The total number of people in the SFU, DTU and NU groups was 743,458 , and 1,116 respectively. There was a considerable similarity in the three groups in terms of the family size; the average family size was 5.7, 5.2, and 5.4 in the SFU, DTU and NU groups respectively. Monthly income measures the standard of living of the household; the average income per household in the SFU, DTU and NU groups was Tk 2,927, Tk 3,038, and Tk 3,626 respectively. These income levels fall in the low-level income group in Bangladesh.

The level of education among the three groups was generally low (Table). About one-third of the population was illiterate in the SFU and NU groups, and one-third had up to 1-5 year(s) of education. The situation was different in the DTU group; more than half of the people had been educated up to 1-5 year(s) in this group while about one-fourth of the people had 6-10 years of education, and a very few had higher education in the three groups. 


\begin{tabular}{|c|c|c|c|}
\hline Characteristics & SFU $(n=142)$ & DTU $(n=81)$ & $\mathrm{NU}(\mathrm{n}=205)$ \\
\hline Total population & 743 & 458 & 1116 \\
\hline Average family size & 5.7 & 5.2 & 5.4 \\
\hline \multicolumn{4}{|c|}{ Occupation of household head, no. (\%) } \\
\hline Farming & $77(56.2)$ & $32(41.6)$ & $129(62.9)$ \\
\hline Business & $9(6.6)$ & $8(10.4)$ & $26(12.7)$ \\
\hline Service & $4(2.9)$ & $0(0)$ & $10(4.9)$ \\
\hline Fisheries & $6(4.4)$ & $6(7.8)$ & $4(2.0)$ \\
\hline Labour-selling & $21(15.3)$ & $14(18.2)$ & $13(6.3)$ \\
\hline Teaching & $10(7.3)$ & $4(5.2)$ & $7(3.4)$ \\
\hline Medical practice & $2(1.5)$ & $1(1.3)$ & $1(0.5)$ \\
\hline Others & $8(5.8)$ & $12(15.6)$ & $15(7.3)$ \\
\hline Average monthly income (Tk) & $2,927 \pm 1,620$ & $3,038 \pm 2,010$ & $3,626 \pm 3,107$ \\
\hline \multicolumn{4}{|c|}{ Education in school (years), no. (\%) } \\
\hline 0 & $211(28.4)$ & $43(9.4)$ & $378(33.9)$ \\
\hline $1-5$ & $279(37.6)$ & $263(57.4)$ & $370(33.2)$ \\
\hline $6-10$ & $174(23.4)$ & $124(27.1)$ & $274(24.6)$ \\
\hline $10-12$ & $75(10.1)$ & $27(5.9)$ & $72(6.5)$ \\
\hline$>12$ & $4(0.5)$ & $1(0.3)$ & $22(1.9)$ \\
\hline \multicolumn{4}{|l|}{ Drinking-water sources, no. (\%) } \\
\hline Domestic shallow tubewell & $74(54)$ & $0(0)$ & $187(91)$ \\
\hline Public shallow tubewell & $56(41)$ & $0(0)$ & $4(2)$ \\
\hline Pond & $0(0)$ & $0(0)$ & $6(3)$ \\
\hline Deep tubewell & $0(0)$ & $73(90)$ & $0(0)$ \\
\hline Others & $6(4)$ & $8(10)$ & $8(4)$ \\
\hline \multicolumn{4}{|l|}{ Cooking-water sources, no. (\%) } \\
\hline Own shallow tubewell & $10(7)$ & $25(31)$ & $29(14)$ \\
\hline Public shallow tubewell & $5(4)$ & $0(0)$ & $1(1)$ \\
\hline Pond & $119(88)$ & $44(54)$ & $168(82)$ \\
\hline Deep tubewell & $0(0)$ & $8(10)$ & $0(0)$ \\
\hline Others & $2(1)$ & $1(1)$ & $6(2)$ \\
\hline \multicolumn{4}{|c|}{ Water consumption (L/day/household) } \\
\hline Drinking & $31 \pm 14$ & $35 \pm 15$ & $31 \pm 19$ \\
\hline Cooking & $35 \pm 16$ & $32 \pm 11$ & $33 \pm 19$ \\
\hline
\end{tabular}

The occupation of head of households was categorized in eight groups, such as farming, business, services, fisheries, labour-selling, teaching, medical practice, and others. A sizeable number of household members were farmers (56\% in the SFU, $42 \%$ in the DTU and 63\% in the NU groups) or labourers $(15 \%$ in the SFU, $18 \%$ in the DTU and $6 \%$ in the NU groups) (Table). Business was next in importance after farming, with $6 \%$ in the SFU, $10 \%$ in the DTU, and $12 \%$ in the NU groups. A significant number of households in the three groups were en- gaged in other occupations, such as teaching, service, and ricksaw/van-pulling. The socioeconomic profiles found in the study reflected a common scenario in rural Bangladesh. Previous studies reported that one-third of the population was illiterate, and the average household income was Tk 3,000-6,000 (10-11).

\section{Pattern of water-use}

The patterns of water-use for drinking and cooking were considerably similar in the three groups (Ta- 
ble). The daily average demand of water for drinking and cooking was the same in the three groups. Each household used about 30-40 litre of water for drinking per day, and the corresponding figure for cooking purpose was the same. The average daily consumption of water per person for drinking was about 5-7 litre. The amount of water used for cooking and drinking determined in this study was similar to the previous study (11). However, Watanabe et al. reported that the water intake per person was three litre per day with substantial individual variation (the maximum=6 litre per day) (12).

The results of the survey showed that most (about 90\%) households, except the DTU group, accessed water for drinking from shallow tubewells (STWs), 95\% in the SFU group, and 93\% in the NU group (Table). This supports the estimation reported in earlier studies that around 97\% of rural households in Bangladesh use groundwater for drinking (13). Both public and domestic tubewells were being used. Most (90\%) DTU households accessed water for drinking from DTWs. About 88\%, 54\%, and $82 \%$ of the households in the SFU, DTU and NU groups respectively accessed water for cooking from surface water, such as pond-water. The percentage of the households using STWs for cooking was $7 \%, 31 \%$, and $14 \%$ in the SFU, DTU and NU groups respectively.

\section{Present situation of arsenic pollution}

Arsenic-testing was performed on water samples from 95 tubewells; the range of concentration of arsenic is shown in Figure 2. About 90\% of the tested tubewell water showed an arsenic content higher than $50 \mu \mathrm{g} / \mathrm{L}$, thus exceeding the arsenic standard set by the Government of Bangladesh. Earlier BAMWSP field-kit testing showed that $79 \%$ of 6,762 tubewells contained more than $50 \mu \mathrm{g} / \mathrm{L}$ arsenic (2) lower than that found in this study. This may be because only a few tubwells $(n=95)$ were

Fig. 2. Range of arsenic in tubewell water $(n=95)$

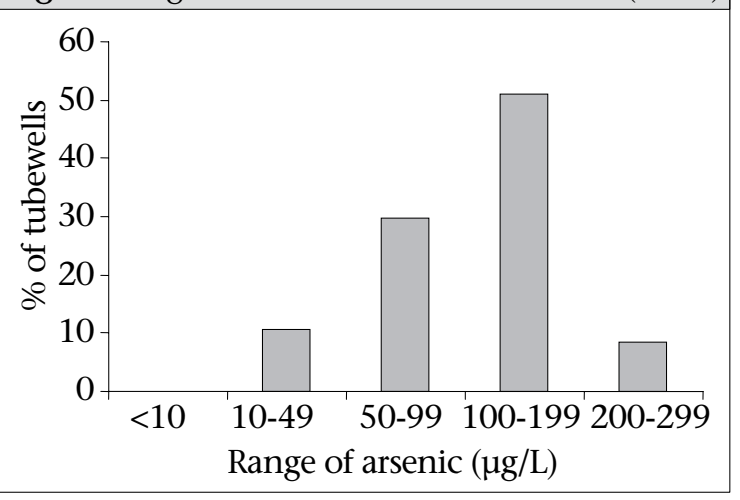

tested in this survey. Moreover, there is a possibility of contamination of tubewells due to seasonal variation (14). Concentration of arsenic in DTW water $(\mathrm{n}=20)$ was $19 \pm 12 \mu \mathrm{g} / \mathrm{L}$, and none of the DTW water samples exceeded the Bangladesh arsenic standard for drinking-water.

\section{Evaluation of SAF}

\section{Arsenic-removal performance}

Figure 3 shows the arsenic-removal data for 41 SAFs monitored in 2006, when most of these monitored filters had been in operation for two years or more. Concentration of arsenic in treated water was reduced to $14 \pm 10 \mu \mathrm{g} / \mathrm{L}$, from an average of $200 \mu \mathrm{g} / \mathrm{L}$ in tubewell water. The average arsenic-removal efficiency was about 93\%. One hundred percent of the filters produced water within the Bangladesh standard of $50 \mu \mathrm{g} / \mathrm{L}$, and $50 \%$ met the WHO standard of $10 \mu \mathrm{g} / \mathrm{L}(15)$. These results demonstrate that the SAF was very efficient and effective during two-year arsenic-removal performance.

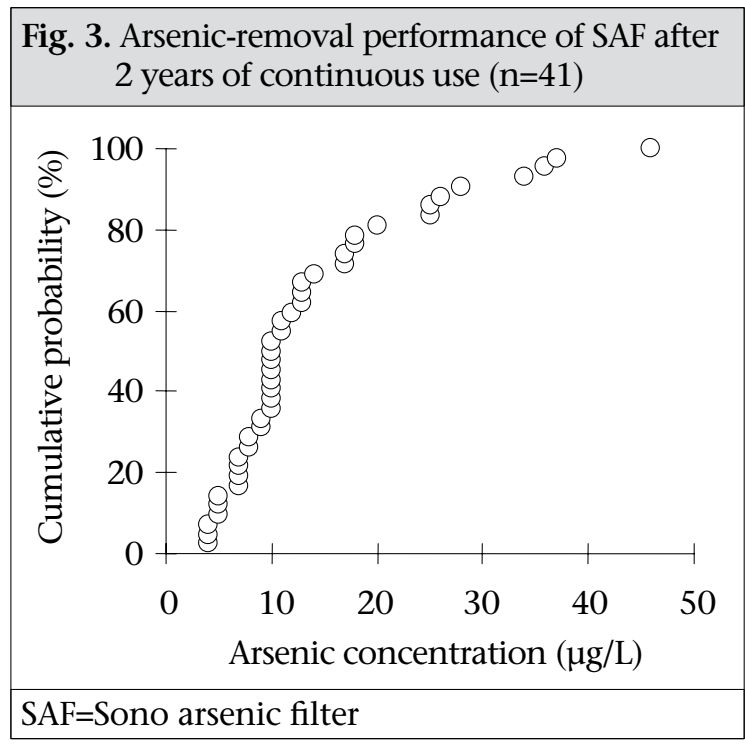

\section{Present situation}

Seventy-two percent (142 SAFs) of the filters were in operation during our survey, and 28\% (56 SAFs) of the filters were out of operation due to their breakage. Thirty-one filters were abandoned after one year, seven filters were broken after six months, and 18 filters were abandoned within six months of installation. The connection between the two buckets had been broken in most damaged filters.

\section{Cleaning and maintenance filter}

The households were asked about the maintenance 
of SAF to clarify the filter maintenance method. ADAMS conducted workshop training on maintenance of filter before providing the filter. Over $80 \%$ of the households had the filter manual. The manual contains complete guidance for cleaning of filter, including washing, changing the top few $\mathrm{cm}$ of sand in the upper bucket, washing the connection tube, and, finally, pouring one or two batch(es) of boiling water to kill microorganism. However, $80 \%$ of the households performed cleaning based only on the workshop training. One of the reasons for not using the manual might be that it was full of textual instructions, not pictorial instructions. However, most (about 80\%) of the households were knowledgeable about the maintenance of filter, and they maintained or regularly cleaned it once or twice a week. Regular cleaning of the filter might be an important reason for the high arsenicremoval performance of SAF.

\section{Sludge disposal}

The households were given guidance on sludgedisposal methods during the workshop training. Clear textual instruction was also given in the filter manual. According to the manual, the sludge was subjected to toxicity-characteristic leaching procedure (TCLP) (16) and was not considered hazardous materials. However, the sludge should be kept in a pot for environmental safety. In this study, we found that most users disposed of sludge either in drains (58\%) or directly in ponds (35\%).

\section{Comments of household}

Finally, the households were told to assess the overall performance of SAF by asking the cost, quality of water, maintenance, clogging problem, and the water filtration rate of the filter. About $35 \%$ of the users said that cost of the filter is low while $6 \%$ said that it is high. Another $59 \%$ of the households did not make any comments regarding its cost. The question was asked based on the cost they have paid (Tk 150), and most (90\%) users did not know about the actual cost of SAF (US\$ 45-50). Forty-five percent of the users were satisfied, $21 \%$ were very satisfied, and a low percentage (4.5\%) of users was not satisfied with the quality of water on the basis of its taste. However, another $29.5 \%$ of the users did not make any comments about the quality of water. About $41 \%$ of the users reported that the filters were frequently clogged and that the flow of water was too slow (about 36\%) to get enough water for their daily needs. About $51 \%$ of the users indicated that the cleaning technique was burden- some for them as the filters have to be carried to the pond for cleaning.

\section{Survey on NU group}

Due to socioeconomic conditions, all the households could not afford or were not willing to buy SAF. Such households were not followed actively due to the limited number of filters provided by ADAMS. Some households abandoned some technologies for various reasons and also were using contaminated tubewells. In this regard, a survey was conducted among the NU group to assess the demand of the arsenic-removal technology. Several questions were asked.

Some households in the NU group had some experience with some arsenic-removal technologies or alternative arsenic-free safe water options. They, however, stopped using the technologies or options for many reasons. Figure 4 shows the arsenicremoval technologies or options previously used by the households and the reason of abandoning them. Of the 205 respondents in the NU group, 56 had used SAFs, and 34 households had used DTWs. Of them, 68 households had explained the reasons. Forty-seven households stopped using SAFs because the filters had broken. Five households had difficulty to collect water from DTWs, which were far from their house. Another five households stopped using DTWs after getting SAFs. High cost, low filtration rate, and the filter-clogging problem were the reasons for abandoning the technologies by another 11 households.

The households in the NU group were using contaminated tubewells to get their drinking-water. Figure 5 shows the reasons for using arsenic-contaminated tubewells given by the 95 households in the

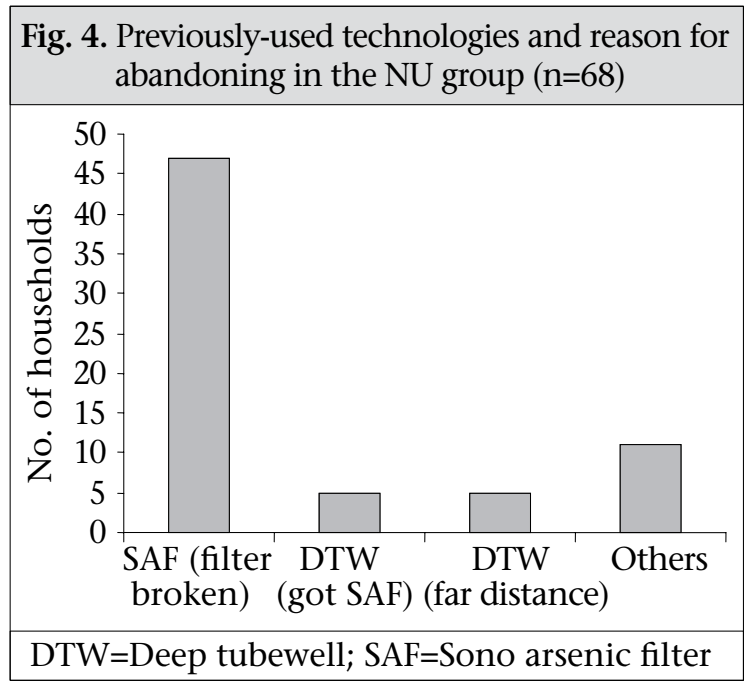




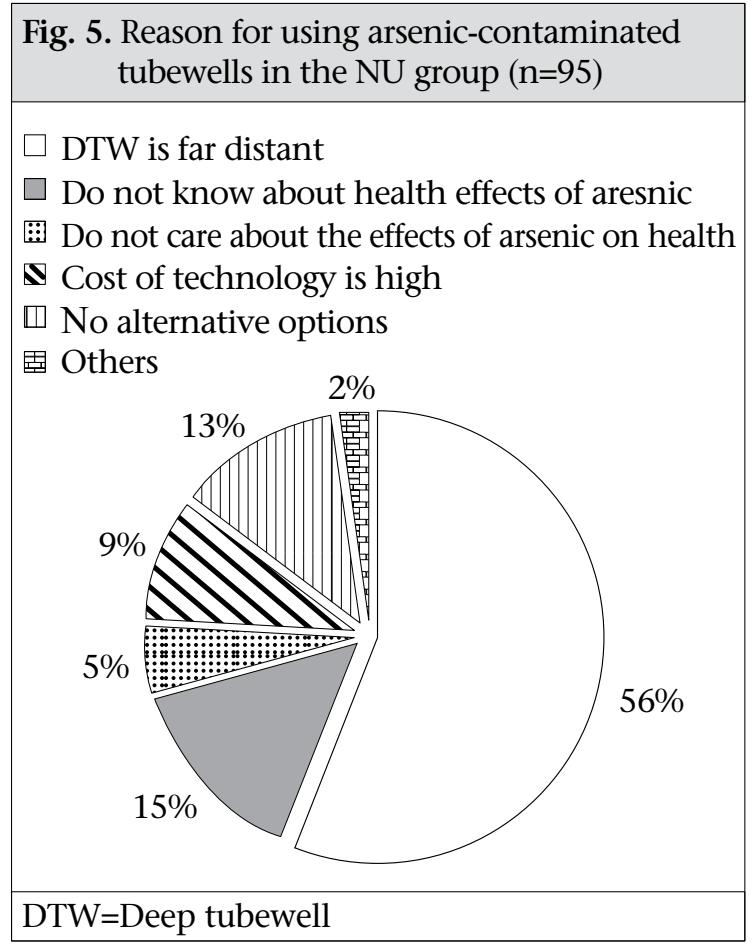

NU group. Of them, 56\% reported that it was difficult for them to use DTWs as the wells were located far from their houses. About 15\% of the households indicated that they did not know about the effects of arsenic on the health. About $13 \%$ of the households had no way or alternative options of arsenicfree water, $9 \%$ were concerned about the high cost, and $5 \%$ indicated that they did not care about the effects of arsenic on health. The results are remarkably similar to the outcome of a survey where the respondents did not switch because a safe well was too far, although many households had previously indicated that they were willing to walk comparable distances (17). Although this survey did not collect well-switching households data, previous studies have shown that well-switching could have had a considerable impact on exposure to arsenic (17-19). The households in the NU group were also asked if they really needed an arsenic mitigation; about 95\% $(n=205)$ of the respondents affirmed that they did.

\section{Households' preferred technologies and will- ingness to pay}

The households were asked about their preferred technologies among the five selected technologies or options after explaining all the technologies in detail, such as initial cost and running cost, quality of water, and convenience of use and health risks. Household filter and DTW were the preferred technologies among the five. About 50\% among the SFU, DTU and NU groups choose household filter as the first option, and about $50 \%$ chose DTW as their option (Fig. 6). The second preference also was either household filter or DTW in all the groups (data not shown). About $2.8 \%$ of the households from the SFU, none from the DTU, and $5.4 \%$ from the NU groups ranked community filter as their first preference. None of the households among the three groups ranked pond-sand filter and rainwater harvesting as their first option. These results were consistent with the previous report that the preferred technologies were DTW and three-pitcher filter (11).

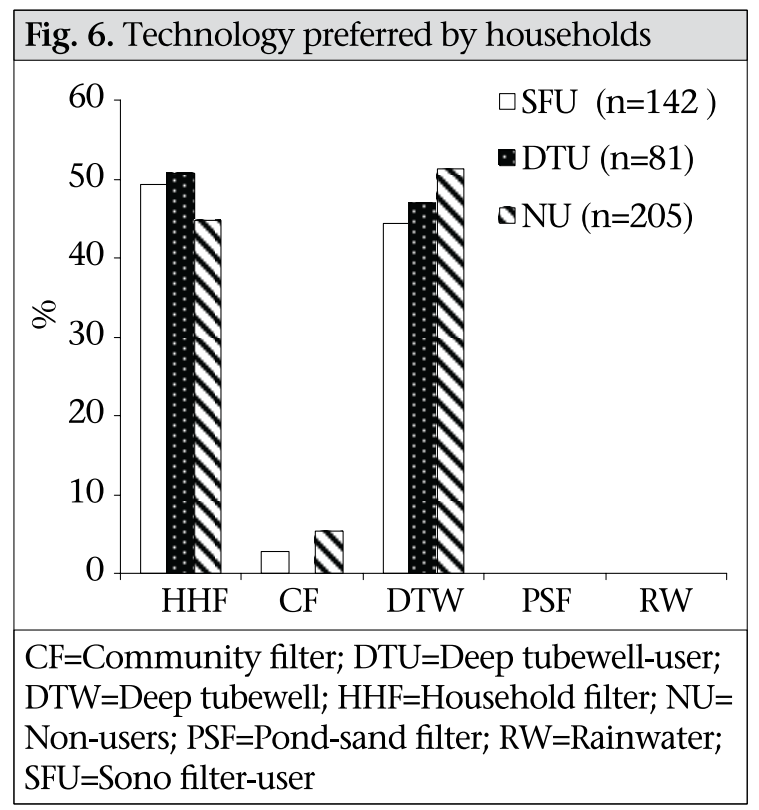

The households were asked about the most important factor of a technology to get arsenic-free water. The majority (50-60\%) of the respondents were very concerned about the quality of water $(50-60 \%$ for all groups) and cost (50-60\% for all groups) of the technology. Water-filtration capacity and maintenance were the second concern among all the groups.

These results indicate a high demand of household arsenic filter in the surveyed area. Therefore, the households were asked whether they were willing to pay for the household filter. Moreover, the households were asked whether they can contribute to the maintenance of the filter and testing the quality of water. Figure 7 shows the households' willingness to pay for the filter. About $70 \%$ of the households expressed their unwillingness to pay for the filter. The ratio was almost same among the groups [(SFU (71\%), DTU (78\%), and NU (69\%)]. However, about $30 \%$ of the households were willing to contribute a little amount (US\$ 1-5) for the filter which was much lower than the actual cost of 


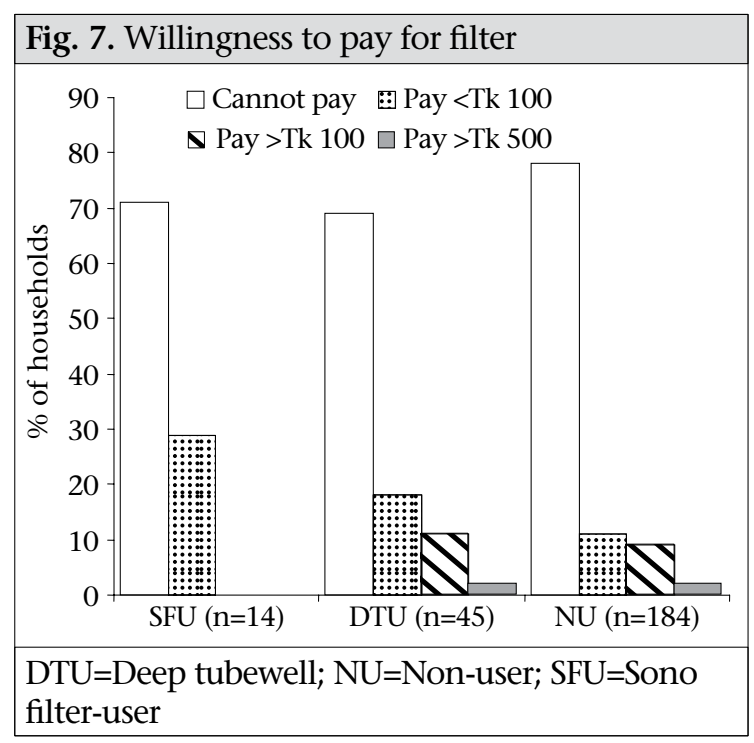

SAF. About $70 \%$ of the households in all the groups did not show any interest to pay, and about 30\% were willing to pay a little ((US\$ 1-2) for the maintenance of filter and testing of the quality of water.

\section{DISCUSSION}

This paper presents the results of the study on arsenic pollution and an extensive technical and social evaluation on SAF. The level of education, occupation, and income in the survey are typical of rural villages in Bangladesh. The finding of the field survey indicates that most $(91 \%, n=205)$ households in the NU group were using their own shallow tubewells, although most of them were contaminated with arsenic. The households in all the groups had shifted the source of cooking water to pond-water instead of arsenic-contaminated tubewells. The possible cause of using pond-water for cooking may be due to insufficiency of arsenicfree tubewell (NU group), insufficient water from the SAF due to slow filtration rate (SFU group), and inconvenience of DTW as it is difficult to collect water from far distance (DTU group).

SAF was found to be technically appropriate for the water condition generally encountered in Bangladesh. After two years of continuous usage, average arsenic removal was about 93\%. These results indicate that SAF would provide arsenic-free water for a long period. However, the abandonment rate of SAF was $28 \%$ in the first year. Inadequate flow of water, broken filters, and unavailability of filter materials were some reasons for abandoning the filter reported by the respondents. Although the filter can easily break, it could also be easily repaired. Some households claimed that replacement parts were not available at the local market. Some respondents were also reluctant to buy the replacement parts on their own. They rather relied upon the provider to repair or replace the filter. This might be because the filter was provided free of charge through the financial support of a donor group. Therefore, if such disincentive were confirmed, it suggests that the beneficiaries should make some contribution for the filter for their ownership.

Another factor is that, although the maintenance or cleaning of SAF seemed to be easy, the filter manual should be more pictorial which can allow better understanding. The results of the survey also suggest that sludge-disposal method should be clearer or specific to avoid the possible future contamination by arsenic in surface water-because arsenic-leaching characteristics in sludge cannot be completely determined by the TCLP extraction procedure. The important environmental factors, such as $\mathrm{pH}$, redox potential, and interaction with other metals, such as iron, were not accounted for in the TCLP and may, thus, predict inaccurate arsenic-leaching potential from the solid wastes (20).

Although SAF was efficient in removal of arsenic, only a few people (30\%) were willing to buy the filter. They seemed to rely upon help from NGO or outside aid. In this investigation, it was assumed by the authors that the lack of ownership caused their reliance on the outside. User's contribution to the SAF could have significant influence on the sustainability of SAF. A previous study has shown that communities (users)-contributed mitigation options were far more likely to be working than when no contribution was made (21). The results of the survey indicate that the implementation approaches of SAF had lack of household participation and long-term sustainability.

However, the abandoned percentage of SAF could be comparable with other mitigation options currently implemented in Bangladesh (7). The National Policy for Arsenic Mitigation and Implementation Plan for Arsenic Mitigation in Bangladesh has promoted the use of community-based dugwells, pond-sand filters, rainwater harvesting, deep tubewells, and piped water as the alternative sources of arsenic-free water supply (7). Some studies have evaluated the sustainability of those options (2123). Kabir and Haward reported that $36 \%$ of those technologies were abandoned during their survey (21). The abandoned percentages also would increase (44\%) if the lower number of deep tubewells is taken into account (21). A study by the Japan International Cooperation Agency found similar results in Jessore district (22). Previous studies also 
have shown that, except deep tubewells, all other mitigation options have had the risk of microbial contamination $(22,24)$. Although the microbial contamination data of SAFs were not collected, the percentage (28\%) of abandoned SAF found in these studies was lower than other technologies or options. Therefore, household-based arsenic-removal technologies are also necessary to take into account the sustainability of the current national policy for arsenic mitigation and implementation.

The results of the survey indicate that convenience is a dominant factor in the choice of use of arsenic-free water. For instance, some households stopped using DTWs as soon as they received SAFs because of the distance factor (Fig. 4). Moreover, 53 households in the NU group did not use DTWs as the wells were far from their house (Fig. 5). On the other hand, the households in the NU group continued to use contaminated water because they have not had any other alternatives. Also, the users who were unconcerned and careless about arsenic poisoning indicated the lack of knowledge about arsenic contamination.

About 70\% of the households were also not willing to pay for filter. This might be because cost of existing filter (SAF) was too high compared to their monthly income. Illiteracy and lack of awareness about the effects of arsenic on health also would be other causes of unwillingness to buy filter. However, households (about 30\%) willing to pay a little (US\$ 1-5) suggested reducing the manufacturing cost of SAF for its sustainability. It is also necessary to develop a low-cost household filter to compete the monopoly market of SAF. In addition, among the five technologies, users' preference of the household arsenic-filtration system indicates that lowcost household arsenic filter could be acceptable to households in rural areas of Bangladesh. A low-cost arsenic-removal technology at the household level would be developed by considering the shortcomings of SAF. However, the technology must pass the environmental technology verification process set by the Government of Bangladesh stated policy for all arsenic-removal technologies for wider deployment.

Success is not only about the development of lowcost technology or reducing the cost of SAF but also about the ability to effectively disseminate the technology, resulting in widespread adoption and sustained use by those in need. To do so, it is necessary to develop an implementation framework based on the social entrepreneur business model, partnership among stakeholders, and long-term capacity- building among local authorities and communitybased organizations to strengthen awareness, and long-term self reliance (25). In the initial stage of filter-implementation activities, a 100\% cash subsidy on the cost of filters may be given by donors to quickly spread the filter among many communities. When awareness increases and demand grows by community development activities, this donor subsidy should be reduced and changed to 50\% cost subsidy. In the final stage, the interested local entrepreneur should be trained on construction, installation, maintenance, and operation of the filter. Once a strong community-based entrepreneurship is developed, users can purchase the filter from the local entrepreneur.

To ensure proper operation and maintenance of filter, holding of continuous workshops for maintenance, operation, and repairing of filter would be necessary. It is also important to monitor the quality of the filtered water through field and laboratory tests. These activities will also encourage people to motivate when the safe water is ensured. The assessment of the quality of water should also be monitored with funds given by the donors. This subsidy should be reduced as implementation activities of the filter progress.

In terms of socioeconomic conditions, the study population is quite similar to the general rural population in Bangladesh. Therefore, the findings of our study regarding evaluation of SAF and proposed implementation framework could be extrapolated to other arsenic-affected areas where SAF or other household-based arsenic filters have been installed or will be introduced.

SAFs was found to be efficient in terms of arsenicremoval performance. The abandoned percentage of SAFs was $28 \%$ in two years, lower than other mitigation options currently implemented in Bangladesh. This finding indicates a need to take into account the household-based arsenic-removal technologies for the sustainability of the current National Policy for Arsenic Mitigation and Implementation. However, the sustainability of SAF suffered due to the breakage of filters, difficulties in the maintenance, proper sludge-disposal guidance, clogging, slow flow-rate, high cost, and lack of ownership. People who were willing to pay and who had preference of household-based arsenic filter recommended the need to develop a low-cost household-based arsenic filter to solve the present groundwater arsenic problem in rural Bangladesh. Development of community-based organization is recommended to ensure the participation of us- 
ers and their contribution towards the long-term sustainability of household-based arsenic-removal technology.

\section{ACKNOWLEDGEMENTS}

This study was funded by the Ministry of Education, Culture, Sports, Science and Technology, Japan. The authors thank KUET and ADAMS teams for their cooperation in this survey.

\section{REFERENCES}

1. British Geological Survey. Arsenic contamination of groundwater in Bangladesh. V. 1-3. Main report. Dhaka: Department of Public Health Engineering, 2000:xvii.

2. National Arsenic Mitigation Information Center. Upazila-wise summary of screening results. Dhaka: National Arsenic Mitigation Information Center, 2004. 2 p. (http://www.bamwsp.org, accessed on 22 September 2008).

3. Chowdhury UK, Biswas BK, Chowdhury TR, Samanta G, Mandal BK, Basu GC et al. Groundwater arsenic contamination in Bangladesh and West Bengal, India. Environ Health Persp 2000;108:393-7.

4. Nickson R, McArthur J, Burgess W, Ahmed KM, Ravenscroft $\mathrm{P}$, Rahman M. Arsenic poisoning of Bangladesh groundwater. Nature 1998;395:338.

5. Yu WH, Harvey CM, Harvey CF. Arsenic groundwater in Bangladesh: a geostatistical and epidemiological framework for evaluating health effects and potential remedies. Water Resourc Res 2003;39:1146-62.

6. Chen Y, Ahsan H. Cancer burden from arsenic in drinking water in Bangladesh. Am J Public Health 2004;94:741-4.

7. Bangladesh, Government of. National Policy for Arsenic Mitigation and Implementation Plan for Arsenic Mitigation in Bangladesh. Dhaka: Government of Bangladesh, 2004:3.

8. Hussam A, Munir AKM. A simple and effective arsenic filter based on composite iron matrix: development and deployed studies for groundwater of Bangladesh. J Environ Sci Health Part A 2007;42:1869-78.

9. Grainger challenge. (http://www.nae.edu/nae/grainger.nsf, accessed on 22 September 2008).

10. Madajewicz M, Pfaff A, van Geen A, Garziano J, Hussein I, Momtaz $\mathrm{H}$ et al. Can information alone change the behavior? Response to arsenic contamination of groundwater in Bangladesh. J Dev Econ 2007;84:731-54.

11. Ahmed J, Goldar BN, Misra S, Jakariya M. Willing to pay for arsenic-free, safe drinking water in Bangladesh (Chapai Nawabganj, Chandpur and Barisal). New Delhi: Water and Sanitation Program-South Asia, World Bank, 2003. 43 p. (http://www.wsp. org/UserFiles/file/36200792328_saarsenicfree.pdf, accessed on 11 June 2009).

12. Watanabe C, Kawata A, Sudo N, Sekiyama M, In- aoka T, Bae M et al. Water intake in an Asian population living in arsenic contaminated area. Toxicol Appl Pharmacol 2004;198:272-82.

13. World Bank. Water and Sanitation Program-South Asia. Arsenic mitigation in West Bengal and Bangladesh: helping households respond to water quality crisis. New Delhi: Water and Sanitation ProgramSouth Asia, World Bank, 2000. 2 p. (Case study no. 3).

14. Savaimuthul X, Hira-Smith MM, Yuan Y, von Ehrenstein OS, Das S, Shosh N. Seasonal variation of arsenic concentrations in tubewells in West Bengal, India. J Health Popul Nutr 2006;24:277-81.

15. World Health Organization. Guidelines for drinkingwater quality. Health criteria and other supporting information [M]. V. 2. Geneva: World Health Organization, 1996:940-9.

16. United States Environmental Protection Agency. Applicability of the toxiciity charactristics leaching procedure to mnieral processing waste. Washington, DC: United States Environmental Protection Agency, 1995:1-7. (RCRA docket no. F-96-PH4A-S0002).

17. van Geen A, Ahmed KM, Seddique AA, Shamsudduha M. Community wells to mitigate the current arsenic crisis in Bangladesh. Bull World Health Organ 2003;81:632-8.

18. Opar A, Pfaff A, Seddique AA, Ahmed KM, Graziano $\mathrm{JH}$, Geen AV. Responses of 6500 households to arsenic mitigation in Araihazar, Bangladesh. Health Place 2007;13:164-72.

19. Chen Y, van Geen A, GrazianoJH, Pfaff A, Madajewicz $\mathrm{M}$, Parvez F et al. Reduction in urinary arsenic levels in response to arsenic mitigation efforts in Araihazar, Bangladesh. Environ Health Perspect 2007;115:917-23.

20. Hopper K, Iskander M, Sivia G, Hussein F, Hsu J, Deguzman $\mathrm{M}$ et al. Toxicity characteristics leaching procedure fails to extract oxoanion-forming elements that are extracted by municipal solid waste leachates. Environ Sci Technol 1998;32:3825-30.

21. Kabir A, Howard G. Sustainability of arsenic mitigation in Bangladesh: results of a functionality survey. Int J Environ Health Res 2007;17:207-18.

22. Japan International Cooperation Agency. Sustainable arsenic mitigation under integrated local government system in Jessore: interim report. Tokyo: Japan International Cooperation Agency, 2007:93-7.

23. Milton AH, Smith W, Dear K, Ng J, Sim M, Ranmuthugala $\mathrm{G}$ et al. A randomized intervention trial to asses two arsenic mitigation options in Bangladesh. J Environ Sci Health Part A 2007;42:1897-908.

24. Howard G, Ahmed MF, Shamsuddin AJ, Mahmud SG, Deere D. Risk assessment of arsenic mitigation options in Bangladesh. J Health Popul Nutr 2006;24:346-55.

25. Murcott S. Co-evolutionary design for development: influences shaping engineering design and implementation in Nepal and the global village. J Int Dev 2007;19:123-44. 